DOI: $\underline{10.20472 / B M .2018 .6 .2 .001 ~}$

\title{
ORGANIZATIONAL CULTURE ASSESSMENT USING THE COMPETING VALUES FRAMEWORK (CVF) IN PUBLIC UNIVERSITIES IN SAUDI ARABIA: A CASE STUDY OF TABUK UNIVERSITY
}

\author{
SALEH HAMED ALHARBI , SELMA SIDAHMED ABEDELRAHIM
}

\begin{abstract}
:
Today the organizational culture $(\mathrm{OC})$ is treated as the main driver in making decisions in organizations and as a critical determiner of their effectiveness. Due to the lack of studies in the field of $\mathrm{OC}$ assessment in Middle Eastern countries and particularly in Saudi Arabia, this study aimed to portray the dominant culture type (Clan, Adhocracy, Hierarchy and Market) in Tabuk University. It also set out to determine the culture type that dominates according to the dimensions of Organizational Culture (Dominant Characteristics, Organizational Leadership, Management Organizational Glue, Strategic Emphases and Criteria for Success) by using an organizational culture assessment instrument (OCAI) based on the Competing Values Framework (CVF). The target population was the Tabuk University workforce $(\mathrm{N}=1999)$. A sample was drawn from the population $(\mathrm{N}=322)$ composed of two categories, academic staff and employees. The study findings indicate that the dominant culture type in Tabuk University is clan culture. However, three other types of culture characteristics are represented in some dimensions (Dominant Characteristics, Organizational Leadership and Management of Employees) besides the clan characteristics. The results indicate that there are statistically significant differences in culture strength according to some respondents' demographic characteristics.
\end{abstract}

\section{Keywords:}

organizational culture, OCAI, CVF

JEL Classification: M10

\section{Authors:}

SALEH HAMED ALHARBI, Tabuk University - Faculty of Business Administration - Department of Management, Saudi Arabia, Email: s.alharbi@ut.edu.sa SELMA SIDAHMED ABEDELRAHIM, Tabuk University - Faculty of Business Administration Department of Management, Saudi Arabia, Email: ss.mohammed@ut.edu.sa

\section{Citation:}

SALEH HAMED ALHARBI , SELMA SIDAHMED ABEDELRAHIM (2018). Organizational Culture Assessment using the Competing Values Framework (CVF) in Public Universities in Saudi Arabia: A Case Study of Tabuk University. International Journal of Business and Management, Vol. VI(2), pp. 1-16., 10.20472/BM.2018.6.2.001 


\section{Introduction:}

Scholars have indicated that organizational performance depends on how broad and strong the values of the culture shared in the organization are (Denison 1990). This means that performance can be improved in the organization when its cultural values are homogeneous with the beliefs and values of its employees (Berson et al. 2007; Ludolf et al. 2017).

Besides, culture can be the source of failure or success of the organization (AutTheresa Schmiedel and Jan vom Brockehors, 2012). The organization must define and determine the type of culture manifested in it if it desires to succeed and achieve its goals. The success of the organization depends on the appropriateness of the organization's culture to the competitive environment of the industry that it works in, and to what extent the organization culture is compatible with its long-term goals, style, and inclinations (Cameron and Quinn, 2006). Most reviews of organizational culture have examined culture in the context of commercial organizations, and there have been only a few investigations into European educational backgrounds (Ferreira and Hill, 2008). OC in the context of higher education needs to be investigated (Ramachandran et al. 2010).

Studies that examined the culture of universities in developing countries, particularly in Saudi Arabia, are rare, so this study explores that context. It aims to identify the culture type manifested in Tabuk University from the perspectives of academic staff and employees and to answer the following research questions. What is the dominant type of culture in Tabuk University? Are there statistically significant differences in the strength of culture according to demographic characteristics?

\section{Literature review:}

Despite the existence of numerous studies in the field of organizational culture, there is no agreement about one definition of it, as there are different views about this concept. The base of OC starts from the national culture which invisibly surrounds many practices in the organization, as it characterizes the values and beliefs of people and controls the practice of organization activities (Peretz and Fried 2012). OC is considered as a unique set of the highest values, standards, basic beliefs and behavioural norms held by the majority of organizational members (Fanxing el al. 2016). Much research focuses on the organization's values, which are the visible reflection of culture (Parker and Bradley, 2000). Also, Chatman and Jehn (1994) stated that OC is an asset of "widely shared and strongly held values". Harry (2014) defined organizational culture as the "personality of an organization, a pattern of shared basic assumptions-values, beliefs and codes of practice that emerged in an organization to achieve its mission and to solve its problems". Such fundamental assumptions were learned by a group as it solved its problems of external adaptation and internal integration, worked well enough to be considered true, and so came to be explained to new members as the correct way to perceive, think, and feel in relation to those problems (Acar, 2012). Culture may be implicitly or explicitly embodied in group consciousness including values, rules of conduct, team consciousness, working style, sense of belonging, and so forth. The consciousness also includes individual behavioural expression and mode of thinking (Fanxing et al. 2016), while Schein (1992) indicated that the organizational culture could be divided into three levels: assumptions, artefacts and values. This is because it has a huge effect on different aspects of organizational behaviour. Another definition was highlighted: "OC is reflected in the values, the dominant leadership styles, language and symbols, procedures and routines, and the definitions of success that make an organization unique" (Cameron and Quinn, 1999). In fact, organizations always have a culture; the difficulties and challenges come when leaders need to manage that culture (Hofstede et al., 1990). 
Scholars and researchers in the 1980s started to pay more attention to the concept of OC, as due to its contribution to the performance of organizations (Ouchi, 1981; Nikpour, 2017). Many scientific studies presented a positive relationship between organizational effectiveness and some dimensions of organizational culture.

Authors such as Denison (1990), Berson et al. (2007), Ahmed and Shafiq (2014), Serpa (2015) and Ludolf et al. (2017) indicated that culture could affect some organizational characteristics such as performance, productivity, quality, commitment and behaviour. Furthermore, the culture profile will be useful for identifying what kinds of leadership attributes are most valued, what behaviours are most likely to be recognized and rewarded, and what kinds of management styles are preferred (Cameron and Quinn, 2006). Moreover, shared values help organizations to predict employees' reaction toward applying a particular role, procedure or strategy, which in turn can assist the organization in avoiding undesired consequences (Hofstede, 2011).

OC can be a source of both failure and success (Schmiedel and vom Brockehors, 2012). So, for this reason it is useful to know an organization's culture type because organizational success depends on the extent to which the organization's culture matches the demands of the competitive environment. From other perspectives, there has been much pressure on higher educational institutions such as universities worldwide in the last two decades to adopt rapid economic, social, technological and political changes in their environment (Beytekin et al., 2010; Bartell, 2003). Moreover, globalization, such as international competition, increases the force of pressures, such as growth competitiveness and complexity of economics and technology. These reasons create much pressure for institutions of higher education to change their environment.

In the last few decades, writers have proposed a variety of dimensions and attributes of organizational culture. For instance, Deal and Kennedy (1982) introduced a measurement for OC based on measures of feedback and risk, where they classified OC into four dimensions: tough-guy macho culture, work/hard/play hard culture, bet your company culture, and finally process culture. Schein (1984) classified OC into three dimensions: Assumptions, Values and Artefacts. Another model for measuring OC was proposed by O'Reilly et al. (1991) which was the Organizational Culture Profile (OCP). This focuses on specific factors of OC, including outcome orientation, attention to detail, respect for people, team orientation and innovation. Another approach was Denison's ( 1990) model for measuring OC which has four dimensions: Involvement, Adaptability, Consistency and Mission.

The most appropriate frameworks for measuring OC characteristics should be based on empirical evidence; in other words, they must be valid and should be able to integrate and organize most of the dimensions being proposed. That is the purpose of using the Competing Values Framework (CVF). CVF (shown in the figure below) is a framework that was empirically derived and has been found to have both face and empirical validity, and helps to integrate many of the dimensions proposed by various authors (Cameron and Quinn, 2006). The CVF is one of the most influential and extensively used models in the area of organizational culture research (Yu and Wu, 2009). 
FIGURE 1: The Competing Values Framework

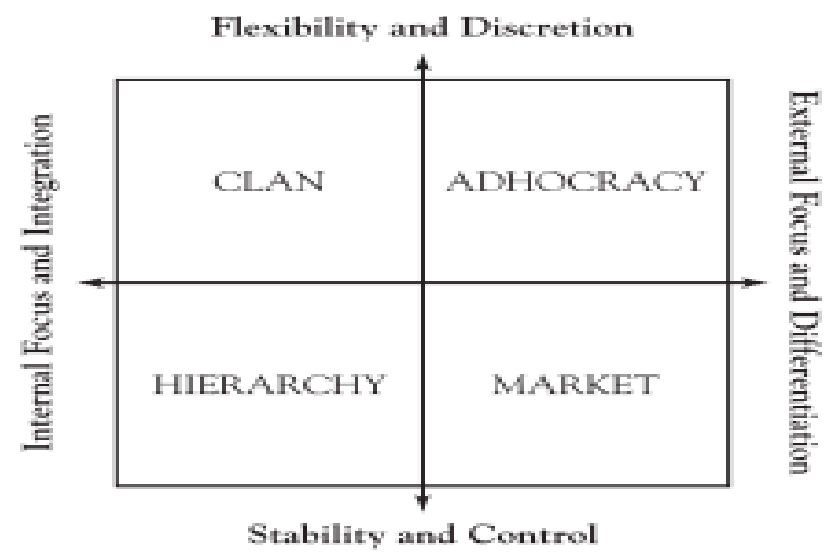

Source: Cameron, K. S. and Quinn, R. E. (2006) Diagnosing and Changing Organizational Culture., The JosseyBass Business \& Management Serie p.35

Although the CVF is labelled competing because the criteria within the model seem conflicting opposites at first, the originators of the framework recognize that the criteria are neither mutually exclusive nor necessarily orthogonal (AutTheresa Schmiedel and Jan vom Brockehors, 2012). In fact, they acknowledge that it is possible and desirable for organizations to take all four perspectives simultaneously.

The CVF was developed initially from research conducted on the significant indicators of effective organizations. CVF is based on two dimensions of effectiveness (Cameron and Quinn, 2006). While Yang and Ryan (2013) indicated that the control-flexibility dimension reflects the extent to which an organization focuses on stability vs change, whereas the internal-external dimension demonstrates the organization's focus on the internal organization vs the external environment. Cameron and Quinn (2006) explained that these two dimensions form four quadrants, each representing a distinct set of organizational effectiveness indicators and form four types of culture

\subsection{Adhocracy (Create) Culture:}

The first quadrant (external focus and differentiation-flexibility and discretion) is labelled "Adhocracy (Create) Culture" and assumes that adaptation and innovativeness lead to new resources and profitability, so stress is laid on creating a picture of the future, organized anarchy and disciplined creativity (Cameron and Quinn, 2006).

\subsection{The clan culture:}

The second quadrant (internal focus and integration-flexibility and discretion) is labelled "Clan (Collaborate) Culture" and seems more like an extended family than an economic entity. The typical characteristics of clan-type firms are teamwork, employee involvement programs, corporate commitment to employees, long-term benefit of individual development and high cohesion and morale. As assessed in the OCAI, it is typified by a friendly place to work where people share a lot of themselves. Leaders are considered as mentors and perhaps even as parent figures. The organization is kept together by loyalty and tradition. Commitment is high. Success is defined regarding internal climate and concern for people. The organization places a premium on teamwork, participation, and consensus. (Cameron and Quinn, 2006). The Clan culture views the most effective leaders as parent figures, team builders, facilitators, nurturers, mentors, and supporters (Cameron and Quinn, 2006). Clan organizations emphasize individual 
development, morale, teamwork, participation, and consensus (Ferreira and Hill, 2008). Involvement and participation of employees foster empowerment and commitment. Committed, satisfied employees produce effectiveness (Cameron and Quinn, 2006). Clan culture portrays the university as an organization that focuses on internal maintenance with flexibility, concern for people, and sensitivity for customers (Ferreira and Hill, 2008). The clan culture is full of shared values and shared goals, an environment of collectivity and common help, and an emphasis on empowerment and employee development ( $\mathrm{Yu}$ and $\mathrm{Wu}, 2009)$. The findings of an empirical investigation revealed that group culture (clan) and adhocracy culture are the most supportive culture types for Individual Readiness For Change IRFC (Haffar, Al-Karaghouli and Ghoneim, 2014)

\subsection{The Hierarchy Culture:}

The third quadrant (internal focus and integration-stability and control) is labelled "Hierarchy (Control) Culture" and is characterized by a formalized and structured place and procedures to govern what people do and how to make the organization stable, predictable and efficient in the long term. Effective leaders are good coordinators and organizers. Maintaining a smoothrunning organization is essential. The long-term interests of the organization are stability, predictability, and efficiency. Formal rules and policies hold the organization together.(Cameron and Quinn, 2006). The hierarchy culture has a clear organizational structure, standardized rules and procedures, strict control, and well-defined responsibilities (Yu and Wu, 2009).

\subsection{A market culture:}

The fourth quadrant (external focus and differentiation-stability and control) is labelled "Market (Compete) Culture" and is oriented toward market transactions with other constituencies to create a competitive advantage (Fanxing Meng et al., 2016). As assessed in the OCAl, is it a results-oriented workplace. Leaders are hard-driving producers and competitors. They are harsh and demanding. The glue that ties the organization together is an accent on winning. The long-term concern is on competing for actions and achieving long-term goals and targets. Success is defined in terms of market share and penetration. Outpacing the competition and market leadership is essential (Cameron and Quinn, 2006). The market culture focuses on the transactions with the environment outside the organization instead of on the internal management (Yu and $\mathrm{Wu}, 2009$ ).

\section{Purpose and Objectives}

The purpose of the study was to describe the dominant culture type of Tabuk University. The study was designed as an evaluation survey for the purpose of exploring and describing Tabuk University's organizational culture. The researchers were also interested in studying if there was any variation in the strength of culture types according to demographic variables

The study was guided by the following objectives.

1. To describe the dominant culture type of Tabuk university from its members' perspective. This objective was subdivided into:

a. Describing the dominant culture type

b. Describing the strength of the culture type;

c. Describing the culture profile in Tabuk University that assists the university management to determine the cultural traits that should be changed or developed to enhance the organizational effectiveness.

2. To find the difference between the culture types according to demographic variables 


\section{Methodology:}

Data were collected by using a modified questionnaire which was adapted from the Organizational Culture Assessment Instrument (OCAI) based on CVF and consisting of 6 domains designed to measure the organizational cultures of Clan, Adhocracy, Hierarchy and Market. Responses were made on a Likert scale. In addition, the questionnaire contained questions about the demographic characteristics of the participants (Age, Position, Length of Service in the University and Educational Qualifications and Experience).

The questionnaire was distributed in both Arabic and English language versions. Back translation was used to minimize distortion in the translation process (Neuman, 2006). This involved translation into Arabic by one translator, then translation of the Arabic version back to English by a second translator, followed by a comparison between the two English versions.

The stratified random sample was taken and the size was determined by using the Steven Thompson equation. The sample size was 322, consisting of employees and academic staff. The questionnaires were distributed to faculties and departments in the University; the number of questionnaires returned was 316 (98\%).

The mean scores were computed, and the results were confirmed by using the Kruskal-Wallis test and post-hoc Mann-Whitney Test (If $\alpha$ is greater than. 05, the null hypothesis will be retained, indicating that there is no significant difference between means).

To determine the content and face validity of the questionnaire, the comments of 15 academic staff in the university was collected. The instrument was confirmed to be valid by using Cronbach's Alpha; the reliabilities of the four organizational culture scales were computed (.932) and the coefficients were Clan (.847), Adhocracy (.842), Market (.647), and Hierarchy orientation (.835). Compared to the previous studies in this area, these values were adequately reliable to conduct this study (Cameron and Quinn, 2006).

\section{Findings:}

The dominant type of culture as shown in table (1) for all respondents appeared to be the Clan culture with the highest mean scores, 3.96 for the whole sample and for the employees and the academic staff, (3.92) and (4.05), respectively. To confirm these results, Mann-Whitney $U$ was performed with the null hypothesis that there was no difference between the mean scores of the four types of culture across the employees and academic staff. The Mann-Whitney $U$ test indicated that the four culture types were significantly different between academic staff as illustrated in table (1).

Table (1): Dominant type of culture in the university verified by Mann-Whitney $U$ test

\begin{tabular}{|c|c|c|c|c|c|c|c|}
\hline & \multirow{2}{*}{$\begin{array}{c}\text { All respondents } \\
\text { Mean }\end{array}$} & \multicolumn{2}{|c|}{ Employees } & \multicolumn{2}{|c|}{ Academic staff } & \multirow{2}{*}{$\begin{array}{l}\text { Mann- } \\
\text { Whitney } \\
\text { U }\end{array}$} & \multirow[t]{2}{*}{ Sig } \\
\hline & & Mean & $\begin{array}{c}\text { mean } \\
\text { rank }\end{array}$ & Mean & $\begin{array}{c}\text { mean } \\
\text { rank }\end{array}$ & & \\
\hline Clan & 3.9619 & 3.9213 & 141.08 & 4.0507 & 160.04 & 9827 & .03 \\
\hline Adhocracy & 3.7876 & 3.7317 & 139.68 & 3.8700 & 161.47 & 9615 & .018 \\
\hline Market & 3.8490 & 3.8230 & 140.39 & 3.9222 & 160.74 & 9723 & .023 \\
\hline
\end{tabular}




\begin{tabular}{|l|l|l|l|l|l|l|l|}
\hline Hierarchy & 3.6929 & 3.7137 & 139.48 & 3.6887 & 161.58 & 9583 & .013 \\
\hline
\end{tabular}

If $\alpha$ is greater than 05, the null hypothesis will be accepted

Table (2) shows that the type of culture prevailing according to the age variable was the Clan culture with the highest mean score (4.06). To confirm this result, the Kruskal-Wallis test was performed with the null hypothesis that there was no difference between mean scores of age groups across the four types of culture. The test result confirmed that there was a statistically significant difference between culture types for different age groups. Pairwise comparisons were obtained from Mann-Whitney $U$ to identify the age groups that differ in terms of mean across the four culture types.

Table (2): Types of culture according to age groups:

\begin{tabular}{|l|l|l|l|l|}
\hline & Clan & Adhocracy & Market & Hierarchy \\
\hline Less than 30 & 3.93 & 3.75 & 3.75 & 3.86 \\
\hline $30-40$ & 3.90 & 3.71 & 3.66 & 3.80 \\
\hline $40-50$ & 3.94 & 3.79 & 3.64 & 3.81 \\
\hline $50-60$ & 4.23 & 4.04 & 3.75 & 4.06 \\
\hline 60 more & 4.33 & 4.11 & 3.61 & 4.28 \\
\hline AVG & 4.06 & 3.88 & 3.68 & 3.96 \\
\hline Kruskal-Wallis test & 13.42 & 10.94 & 14.27 & 15.99 \\
\hline Sig* & .009 & .027 & .006 & .003 \\
\hline
\end{tabular}

${ }^{*}$ The significant level is .05

In table (3) the Mann-Whitney test indicated the four culture types were significantly different between the group of $\mathbf{5 0}$ to less than $\mathbf{6 0}$ years and that of less than $\mathbf{3 0}$ years old. Also, the Mann-Whitney test indicated that the four culture types were significantly different between the age group 50 to less than 60 and $\mathbf{3 0}$ to Less than $\mathbf{4 0}$ years old. Only clan, market and hierarchy cultures proved to be significantly different between the age group $\mathbf{5 0}$ to less than 60. And that ranged between $\mathbf{4 0}$ to less than $\mathbf{5 0}$.

Table 3: The Mann-Whitney test result of age group Comparison

\begin{tabular}{|l|l|l|l|l|l|}
\hline Pairwise Comparisons & & Clan & Adhocracy & Market & Hierarchy \\
\hline Less than 30 & mean rank & 48.80 & 48.47 & 48.20 & 48.78 \\
\hline $50-60$ & mean rank & 34.97 & 35.19 & 35.36 & 34.98 \\
\hline $\begin{array}{l}\text { Less than 30 } \\
\text { versus } \\
50-60\end{array}$ & $\begin{array}{l}\text { Mann- } \\
\text { Whitney U }\end{array}$ & $\mathbf{5 0 2}$ & $\mathbf{5 1 3}$ & $\mathbf{5 2 1}$ & $\mathbf{5 0 3}$ \\
\cline { 2 - 6 } & Sig & $\mathbf{. 0 0 4}$ &. $\mathbf{0 0 6}$ &. $\mathbf{0 0 7}$ & .003 \\
\hline 30-40 & mean rank & 75.13 & 75.74 & 75.25 & 74.98 \\
\hline $50-60$ & mean rank & 101.98 & 99.55 & 101.48 & 102.58 \\
\hline
\end{tabular}




\begin{tabular}{|l|l|l|l|l|l|}
\hline $\begin{array}{l}\text { 30-40 } \\
\text { Versus } \\
50-60\end{array}$ & $\begin{array}{l}\text { Mann- } \\
\text { Whitney U }\end{array}$ & $\mathbf{1 3 6 0}$ & $\mathbf{1 4 3 8}$ & $\mathbf{1 3 7 6}$ & $\mathbf{1 3 4 1}$ \\
\cline { 2 - 6 } & Sig & .001 & .005 & .001 & .001 \\
\hline $40-50$ & mean rank & 53.63 & - & 53.60 & 53.53 \\
\hline $50-60$ & mean rank & 69.34 & - & 69.41 & 69.59 \\
\hline $\begin{array}{l}40-50 \\
\text { Versus } \\
50-60\end{array}$ & $\begin{array}{l}\text { Mann- } \\
\text { Whitney U }\end{array}$ & $\mathbf{9 6 5}$ & - & $\mathbf{9 6 3}$ & 957 \\
\cline { 2 - 7 } & Sig & .014 & - & .015 & .013 \\
\hline
\end{tabular}

In table (4) the dominant type of culture according to the years of work in the university is Clan for all years of workgroups with the highest mean score (4.05). To confirm these results, a Kruskal-Wallis test was performed with the null hypothesis that there was no difference between means of culture types across the years of work groups. The test confirmed that there was no statistically significant difference between the culture types for years of work groups.

Table (4): Type of culture according to years of work in Tabuk University verified by Kruskal Wallis Test:

\begin{tabular}{|l|r|r|r|r|}
\hline Years of work & CLAN & ADHOCRCAY & MARKET & HIERARCHY \\
\hline $1.00-3.99$ & 3.95 & 3.85 & 3.91 & 3.86 \\
\hline $4.00-6.99$ & 4.19 & 4.00 & 3.88 & 3.88 \\
\hline $7.00-9.99$ & 4.02 & 3.87 & 3.90 & 3.89 \\
\hline $10.00-12.99$ & 3.91 & 3.72 & 3.81 & 3.77 \\
\hline AVG & $\mathbf{4 . 0 5}$ & $\mathbf{3 . 8 9}$ & $\mathbf{3 . 8 8}$ & $\mathbf{3 . 8 6}$ \\
\hline Kruskal-Wallis test & $\mathbf{8 . 7 3}$ & $\mathbf{8 . 9 7}$ & $\mathbf{7 . 7 3}$ & $\mathbf{5 . 4 7}$ \\
\hline Sig. &. $\mathbf{0 6 8}$ & $\mathbf{0 6 2}$ & $\mathbf{1 0 2}$ & $\mathbf{2 4 2}$ \\
\hline
\end{tabular}

Table (5) shows that the highest mean scores according to years of experience was for clan culture across all years of experience groups. To confirm this result, a Kruskal-Wallis test was performed with the null hypothesis that there was no difference between the means of the four types of culture according to years of experience groups. The Kruskal-Wallis test showed that there was a statistically significant difference between the clan and hierarchy culture types between years of experience groups $x 2(7)=24.762 p=.001$. To indicate which group can be considered as different from the other groups, a Mann-Whitney $U$ test was performed as a posthoc test. The Mann-Whitney test showed there were significant differences between the dominance of Clan culture and the Hierarchy type in the (20.00-24.00 and 30.00-34.00) years of experience groups. 
Table (5): Type of culture according to years of experience verified by Kruskal-Wallis test:

\begin{tabular}{|c|l|l|l|l|l|l|l|l|l|}
\hline $\begin{array}{r}\text { Years of } \\
\text { experience }\end{array}$ & 5.00 & $\begin{array}{l}5.00 \\
-\end{array}$ & 10.00 & $\begin{array}{l}15.00 \\
-\end{array}$ & 20.00 & 25.00 & 30.00 & 35.00 & $\begin{array}{l}\text { Kruskal- } \\
\text { Wallis } \\
\text { test }\end{array}$ \\
\hline CLAN & 4.02 & 4.06 & 3.99 & 3.98 & 4.30 & 4.09 & 4.75 & 4.00 & .225. \\
\hline ADHOCRACY & 3.89 & 3.85 & 3.79 & 3.89 & 4.17 & 3.82 & 4.75 & 4.00 & .162 \\
\hline MARKET & 3.96 & 3.85 & 3.81 & 3.78 & 4.13 & 4.09 & 4.75 & 3.00 & .054 \\
\hline HIERARCHY & 3.96 & 3.88 & 3.75 & 3.64 & 4.09 & 4.09 & 5.00 & 3.00 & .001 \\
\hline
\end{tabular}

The dominant type of culture according to qualifications as shown in table (6) is Clan for all respondents across qualifications categories, with the highest mean score (3.97). To confirm this result, a Kruskal-Wallis test was performed with the null hypothesis that there was no difference between the means of the four types of culture according to qualifications categories. The Kruskal-Wallis test confirmed that there were statistically significant differences between the clan and the adhocracy and the market culture types x2 (5) = 17.795 and 11.668, respectively, $p=.003$ and. 040 . A Mann-Whitney $U$ test was performed as a post-hoc test to indicate which education levels differed towards these culture types. The Mann-Whitney test showed that the adhocracy culture type was significantly different between $\mathrm{PhD}$ degree, (mean rank $=72.45$ ) and diploma (mean rank $=55.55$ ), $U=1149.500, p=.028$. The adhocracy and market culture types were significantly different between PhD degree (mean rank $=113.29$ and 110.65 , respectively) and graduate degree (mean rank $=83.90$ and 87.11 respectively, $U=3456$ and $3744, p=.000$ and. 002). The adhocracy culture type was significantly different between PhD degree (mean rank $=76.74$ ) and M.Sc. (mean rank =59.30, $U=1445.500, p=.020$ ).

Table (6): Type of culture according to qualifications

\begin{tabular}{|l|r|r|r|r|}
\hline & \multicolumn{2}{|l|}{ Clan } & \multicolumn{1}{l}{ Adhocracy } & \multicolumn{1}{l}{ Market } \\
\hline Primary & 4.1111 & 4.0556 & 4.1111 & 3.9444 \\
\hline Secondary & 4.0376 & 3.8661 & 3.8710 & 3.8441 \\
\hline Diploma & 3.8320 & 3.6607 & 3.5807 & 3.6905 \\
\hline Graduate & 3.8039 & 3.6333 & 3.6678 & 3.7731 \\
\hline Master & 3.9286 & 3.7317 & 3.4947 & 3.84285 \\
\hline Doctorate & 4.1272 & 3.9703 & 3.7489 & 3.9710 \\
\hline AVG & 3.9734 & 3.8196 & 3.7457 & 3.8443 \\
\hline Kruskal-Wallis test & .054 & .003 & .040 & .053 \\
\hline
\end{tabular}


Table (7) showed the highest mean scores on the organizational culture dimensions for the university. The highest mean score was in the Dominant Characteristics dimension (Mean=4.2524), while the lowest mean score recorded was in the Strategic Emphases dimension (Mean= 3.8195).

The cultural profile that shaped the university proved to be composed of Clan, Market and Hierarchy cultures. To confirm this result, a Kruskal-Wallis Test was performed with the null hypothesis that there was no difference between the culture types across the dimensions. The test revealed that there was a statistically significant difference between the clan (dominant) and other three culture types for the following dimensions: Dominant Characteristics, Organizational Leadership and Management of Employees $\times 2$ (3) $=23.623,66.03$ and 34.229, respectively, $p=. .000, .000$ and. 000 .

Table (7): The dominant culture on Organizational Culture Dimensions

\begin{tabular}{|l|l|l|l|l|l|}
\hline \multirow{2}{*}{ Dimensions } & \multicolumn{4}{|c|}{ Mean scores } & \multirow{2}{*}{ Type of culture } \\
\cline { 2 - 5 } & Clan & Adhocracy & Market & Hierarchy & \\
\hline Dominant Characteristics & 4.2524 & 3.9353 & 3.9674 & 3.9643 & Clan \\
\hline Organizational Leadership & 3.9675 & 3.8641 & 3.2548 & 3.7226 & Clan \\
\hline $\begin{array}{l}\text { Management } \\
\text { Employees }\end{array}$ & 3.8871 & 3.4175 & 3.6375 & 3.6981 & Clan \\
\hline Organization Glue & 4.0677 & 3.9871 & 4.0903 & 4.0484 & Market \\
\hline Strategic Emphases & 3.6871 & 3.7282 & 3.7864 & 3.8194 & Hierarchy \\
\hline Criteria of Success & 3.9097 & 3.7935 & 3.8770 & 3.8414 & Clan \\
\hline
\end{tabular}

\section{Discussion}

As this study used CVF to measure and assess the OC of Saudi public universities, where CVF was originally used to evaluate and assess the OC of companies, this model is also used by other researchers such as Fralinger and Olson (2007), Beytekin et al. (2010) and Ramachandran et al. (2011) to assess higher education institutions, and confirmed its applicability in higher education settings. This study depicts that the Clan culture is the dominant culture type in Tabuk University from the perspective of its members, with the highest mean score (3.96) where this result matched as other studies' findings indicated. For example, Berrio (2003) found that two-thirds of USA colleges and universities present Clan Culture. Also, Ramachandran et al. (2011) found that the dominant culture in public higher education institutions in Malaysia was Clan. The Clan culture emphasized teamwork, employee involvement programs, corporate commitment to employees, long-term benefit of individual development, as well as high cohesion, morale and collaboration. This implies that the University of Tabuk is in a good position to change and enhance its culture practice and management. Also, the results indicate that there is a difference in the presence of characteristics of culture types according to employment, age groups, years of experience and qualification levels, and there is agreement across the demographic characteristics about the clan culture. Moreover, the clan culture shapes the four dimensions of organizational culture, 
Dominant Characteristics, Organizational Leadership, Management of Employees and Criteria of Success, suggesting that the Clan culture might be the most effective culture type for colleges and universities (Berrio, 2003). The reason that Clan culture is dominant at the University of Tabuk might be explained by the structure of social culture of Saudi society.

Table (1) indicated that the values and assumptions of Clan culture were shaping the identity of the University of Tabuk. As stated by Schein (1992), where shared values among organization members provide common directions and guidelines for members' behaviour, that contributes as a key factor to achieve an organization's goals through high performance. Moreover the main feature of Clan culture are that leaders see their organization as a parent figure and this is a major indicator that the $\mathrm{OC}$ in the university reflects the social culture of Saudi Arabia, consistent with Hofstede's (1980) argument that national culture affects the practice and behaviour of organizations, where it fit with Hofstede's culture dimension and specifically this practice fits with collective orientation. The academic staff and employees had a strong orientation towards the prevalence of clan characteristics in the university, as shown by high mean scores (4.05 and 3.92 respectively). However, the Mann-Whitney $U$ test confirmed that the presence of characteristics of the clan culture type in the university was more strongly perceived by academic staff. Given that academic staff and leaders at public universities are regularly getting training organized by the Ministry of Higher Education here in Saudi Arabia, this may offer the explanation that the dominant culture was a clan because academic staff at the university show commitment and loyalty which this represents as an element of Clan culture.

Two dimensions of organizational culture (Organization Glue and Strategic Emphases) displayed a distinctive profile from the overall culture profile exhibited by Tabuk University. A Kruskal-Wallis test revealed that there was a statistically significant difference between culture types for the following dimensions: Dominant Characteristics, Organizational Leadership, and Management of Employees. This result indicates that in these dimensions the characteristics of clan culture were manifested. On the other hand, these findings suggest that the university possesses a combination of the core characteristics of the dominant Clan culture with those of the less dominant Market culture type when it comes to the area of Organization Glue. The dominant Clan culture and those of the less dominant Hierarchy culture type when it comes to the area of Strategic Emphases and Criteria of Success, and those of dominant Clan with those of the less dominant other types are consistent with the view that organizations are unlikely to reflect only one type of culture but have a combination of more than one culture (Bartell, 2003; Ramachandran et al., 2011). The type of culture in any organization does not belong entirely to just one quadrant but is represented by a mix of characteristics that refer to many types of culture (Quinn, 1988). In fact, the models do not contain organizations. Instead, the organizations include the profile; that is, in every organization, all four types of culture exist (Marcy, 2016).

In sum the dominant culture of Tabuk University, which is a public university, is Clan which implies that employees and academic members of staff perceive the university as an organization that focuses on internal maintenance with flexibility and shows concern for people by providing a supportive workplace, fosters teamwork, and encourages workers to participate. An element of clan culture is commitment and loyalty to the government. It also shows that participants collaborate with each other to achieve the university's goals and tasks, which is in line with the findings of Ramachandran et al. (2011) in a public university in Malaysia. Moreover, the finding that the University of Tabuk represents a clan culture can be explained by the fact that the university is committed to government requirements and the participants conform to the social culture (Hofstede, 1980). Likewise, the findings of this study are in line with the findings 
of Berrio (2003) who comments that almost two-thirds of the studies conducted in the USA show that colleges and universities represent a Clan culture.

Organizational structure varies from one organization to another depending on types of organization, culture of the organization, and whether they share things in common, especially if they operate in the same society. Also, the structure of organizations is partially defined such that that by shaping all procedures which bring about the achievement of tasks, where the culture of universities reflect conditions around everyone in the university-lecturers, employees, and students - the environment in the university has a direct link to culture. That means all universities have a culture that may be strong or weak or mixed. That, in turn, would have an influence on students, such as when the university adopts or promotes the development culture or innovation culture; this culture needs a comprehensive work of administrative staff and lectures, which in turn can develop the disciplines and improve or reform scientific research and teaching. This, in turn, affects the students and their quality of degree.

\section{Implications for public universities}

The finding of this study reveals a number of possible explanations for management and policymakers. The finding suggests that managers at the university possess a limited capacity to isolate management practice from society practice since the dimension of clan were determined for the university. This suggests that the management of the public sector remains different from the private sector in the same society or context. Therefore, the implication for the administration of the University of Tabuk is to improve their practice and procedure of management to keep with the best process practice that helps the university to achieve its goals.

As the main goal of major universities around the world is education, values and beliefs in the universities are the main sources shaping its culture, which in turn affect its behaviour as indicated above. Instead of describing the culture of campuses, researchers should move from traditional research to take the pattern of linking culture to the improvement and success of universities. This should be taken into account when they are investigating the public sector. Moreover, another explanation of this finding is that the public sector differs from private organizations in many ways such as diversity at the workplace and the nature of the organization and the access to resource, flexibility and activities. Public universities operate within the confines of government strategy and policy. More important is that motives and values of public sector employees may differ from those of their private sector counterparts.

\section{Conclusion and suggestion for further research}

Qualifications are products of universities granted to students who satisfied all graduates' module requirements; therefore, in the real world the public and private sectors in almost all countries have some knowledge about candidates who applied to get a job. So employers may at a certain stage while interviewing them consider the weight of the university or colleges that the candidate graduated from. So, as indicated in the above literature, OC has contributed to organizations' effectiveness and performance. Thus universities, since they need their graduates to be recognized as competing candidates, should pay considerable attention to improving weaknesses in their culture's features.

Each society has their own culture; therefore, organizations that operate at that society may share some values from surrounding societies, where an impossible task for organizations is that of determining a culture that is appropriate because of the external environment. Early research on culture was used to describe the culture of institutions in the twenty-first century, and this concept has moved to become the link culture of organizations with success and improvement. Organizations should develop a culture that helps to achieve their goals by 
knowing the weakness of their culture that may benefit to develop values towards their strategic plan because $\mathrm{OC}$ is one of the factors that explain organization performance. The study findings show that public universities' dominant culture was Clan, where this finding suggests that the University of Tabuk needs to reduce the disadvantages of its clan culture and improve the advantages of other culture types. Changing culture is a challenging task achieved by convincing academic members and employees to adopt a better one gradually. Further, researchers are encouraged to conduct a comparison of private and public sectors using the CVF model or any other instrument discussed above or in the literature on exploring universities in the culture of Saudi Arabia.

\section{References:}

Acar, A. Z. (2012) 'Organizational Culture, Leadership Styles and Organizational Commitment in Turkish Logistics Industry', Procedia - Social and Behavioral Sciences, 58, pp. 217-226. doi: 10.1016/j.sbspro.2012.09.995.

Ahmed, M. and Shafiq, S. (2014) The impact of organizational culture on organizational performance: A case study of telecom sector. Global Journal of Management \& Business Research, Vol 14 issu 3 pp 21-30.

AutTheresa Schmiedel and Jan vom Brockehors, F. (2012) 'Article information': Emerald (Which cultural values matter to business process management? Results from a global Delphi study). doi: 10.1108/MBE-09-2016-0047.

Berson, Y., Oreg, S., and Dvir, T. (2007) CEO values, organizational culture and firm outcome. Journal of Organizational Behavior. Vol 29 iss0000 pp. 615-633.

Berrio, A. (2003) 'An Organizational Culture Assessment Using the Competing Values Framework: A Profile of Ohio State University Extension', Journal of Extension. Vol, 41, issue 2. Pp. 206-223.

Cameron, K.S. and Quinn, R.E. (1999) Diagnosing and Changing Organisational Culture: Based on the Competing Values Framework, Addison-Wesley, Reading, UK.

Cameron, K. S. and Quinn, R. E. (2006) Diagnosing and Changing Organizational Culture, The JosseyBass Business \& Management Series. doi: 10.1111/j.1744-6570.2006.00052_5.x.

Chatman, J. and Jehn, K. (1994) "Assessing the relationship between industry characteristics and organizational culture: How different can you be?" Academy of Management Journal. Vol. 37. Iss 3. pp. 522-553.

Deal. T. E. and Kennedy, A. A. (1982). Corporate Cultures: The Rites and Rituals of Corporate. AddisonWesley. Boston.

Denison, D. R. (1990) Corporate Culture and Organisational Effectiveness, Wiley, New York.

Fanxing Meng, Xiaomei Wang, Huajiao Chen, Jin Zhang, Wei Yang, Jin Wang, Q. Z. (2016) 'The influence of organizational culture on talent management: A case study of a real estate company', Journal of Chinese Human Resource Management, 7(2), pp. 129-146.

Ferreira, A. I. and Hill, M. M. (2008) 'Organisational cultures in public and private Portuguese universities: A case study', Higher Education, 55(6), pp. 637-650. doi: 10.1007/s10734-007-9080-6.

Haffar, M., Al-Karaghouli, W. and Ghoneim, A. (2014) 'An empirical investigation of the influence of organizational culture on individual readiness for change in Syrian manufacturing organizations', Journal of Organizational Change Management, 27(1), pp. 5-22. doi: 10.1108/JOCM-04-20120046. 
Harry de Boer (2014) Exploring organizational culture in Saudi Arabian higher education, Interim report, Center for Higher Education Policy Study.

Hofstede, G. (1980) Culture's Consequences: International Differences in World Related Values, Sage Publications, Beverly Hills, AC.

Hofstede, G., Neuijen, B., Ohayv, V., \& Samder, G., (1990) Measuring organizational Cultures: A qualitative and quantitative study across twenty cases. Administrative Science Quarterly, Vol 35, iss 2 pp. 286-316.

Hofstede, G. (2011) Dimensionalizing Cultures: The Hofstede Model in Context. Online Reading in Psychology and Culture, 2(1) https://doi.org/10.9707/2307-0919.1014.

Howard, L.W. (1998) Validating the competing value model as a representation of organizational culture. International Journal of Orginsational Analysis, Vol. 6 Issu 3. Pp. 231-250.

Ludofl, N., Silva, M., Gomes, C., and Oliveira, V. (2017) The organizational culture and values alignment management importance for successful business. Brazilian Journal if Operations \& Production Management, Vol 14. Iss 2. pp. 272-280.

Neuman, L. (2006). Social research methods: Qualitative and quantitative approach. (6 $6^{\text {th }}$ ed). Boston, MA: Allyn and Bacon.

Nikpour, A. (2017). The impact of organizational culture on organizational performance: The mediating role of employee's organizational commitment. International Journal of Organizational Leadership. Vol.6. pp. 65-72.

Marcy, E. L. and R. (2016) 'Article information': emerald (The competing values framework Implications for strategic leadership, change and learning in public organizations). doi: 10.1108/MBE-09-20160047.

O'Reilly, C. A., Chatman, J. A., and Caldwell, D. F. (1991). People amd organizational culture: A profile comparison approach to person-organization fit. Academy of Mangement Journal, Vol. 34, issu. 3. Pp. 487-516.

Ouchi, W. (1981) Theory, Z. How American businesses can meet the Japanese challenges. Reading: Addison-Wesley.

Parker, B. and Bradley, L. (2000) Organisational culture in the public sector: evidence from six organisations. International Journal of Public Sector Management, Vol 13, Iss 2 pp. 125-141.

Peretz, H. \& Fried, Y. (2012) "National culture, performance appraisal practice, and organizational absenteeism and turnover: A study across 21 countries," Journal of Applied Psychology, Vol 97, no. 2: 448-459.

Ramachandran, S.D., Chong. S. C., and Ismail, H. (2011) Organisational culture An exploratory study comparing faculties perspectives within public and private universities in Malaysia. International Journal of Educational Management. Vol. 25, Issu 6. Pp. 615-634.

Schein, E. H. (1984). Coming to a new awareness of organizational culture. Sloan Mangement Review. Vol. 25, issu 2. Pp. 3-16.

Schein, E. H. (1992). Organizational culture and Leadership (2nd ed). San Francisco: Jossey-Bass.

Serpa, S. (2015) The non-sharing of organisational culture: a case study examining the management perspective. Asian Social Science, Vol 11. Issu 10. Pp. 221-230.

Yu, T. and Wu, N. (2009) 'A Review of study on the competing values framework', International Journal 
of Business and Management, 4(7), pp. 37-42. doi: 10.5539/ijbm.v4n7p37. 